\title{
An investigation on How Community Pharmacies and Herbalist's Shops manage patients with probable Oral Cancer
}

\author{
Rabiei $\mathbf{M}^{1}$, Yousefbeyk $\mathrm{F}^{2}$, Ghasemi $\mathrm{S}^{3}$, Pirzamanbin $\mathrm{S}^{4}$ \\ ${ }^{1}$ Associate Professor, Oral \& Maxillofacial Medicine Dept,Faculty of Dentistry, Guilan University of Medical Sciences, Rasht, Iran. \\ ${ }^{2}$ Assistant Professor, Pharmcognosy Dept, School of Pharmacy, Guilan University of Medical Sciences, Rasht, Iran. \\ ${ }^{3}$ Assistant Professor, Medicinal Chemistry Dept, School of Pharmacy, Guilan University of Medical Sciences, Rasht, Iran. \\ ${ }^{4}$ Dentist
}

\begin{tabular}{l}
\hline ARTICLE INFO \\
\hline Article Type \\
Orginal Article \\
\hline Article History \\
Received: June 2015 \\
Accepted: Oct 2016 \\
ePublished: March 2016 \\
Keywords: \\
Oral cancer, \\
Community pharmacies, \\
Community pharmacy services, \\
Herbal treatment
\end{tabular}

\begin{abstract}
Background and Aim: Oral cancer is a serious health problem, mainly in cases with late diagnosis. The objective of this study was to investigate the role of community pharmacists, community pharmacy assistants and herbalists in late stage diagnosis of oral cancer.

Methods and Materials: A cross-sectional study by the standardized simulated patient approach was undertaken to investigate the recommendation given to a potential cancer patient at pharmacies and herbalists' shops in Rasht, Iran. The introductory statement was "My father is 63 years old and he is a smoker who has a painful ulceration on his tongue for about 6 months which wasn't painful at first but is painful now. What would be your recommendation? "All the responses were noted and transferred to data sheets. The recommendations were analyzed separately and then grouped. Recommended therapies and their administrations were also recorded.

Results: The results showed that $73 \%$ of community pharmacies referred patients to primary medical care systems. Community pharmacists and community pharmacy assistants had closely equal roles $(74.3 \%$ and $72.5 \%$, respectively). Contrariwise, only $7.1 \%$ of herbalists referred patients with oral ulcers to a physician or a dentist. Almost $10 \%$ of the pharmacies recommended OTC drugs only and $11 \%$ prescribed medications combined with referral to a medical or dental practitioner for consultation. In reverse, $78.6 \%$ of herbalists recommended an OTC remedy and none of them advised patients to visit a GP or dentist accompanied by prescribing an herbal remedy.

Conclusion: Herbalists have a potential role in diagnostic delay in patients with oral cancer.
\end{abstract}

\footnotetext{
Please cite this paper as:

Rabiei M, Yousefbeyk F, Ghasemi S, Miraba S, Pirzamanbin S. An investigation on How Community Pharmacies and Herbalist's Shops manage patients with probable Oral Cancer. J Res Dent Maxillofac Sci.2016;1 (2):1-6.
}

*Corresponding author: Fatemeh Yousefbeyk 


\section{Introduction:}

Oral cancer as a major health problem comprises over $90 \%$ of the malignancies in oral and maxillofacial region. ${ }^{(1,2)}$ The risk of oral cancer is higher in those aged more than 65 years, black males and chronic alcohol and tobacco users. ${ }^{(1)}$ World Health Organization (WHO) has reported oral cancer as the sixth most common cancer in males after lung, prostrate, colorectal, stomach, and bladder cancer while in females it is the tenth most common cancer after breast, colorectal, lung, stomach, uterus, cervix, ovary, bladder, and liver cancer. ${ }^{(3)}$ The worldwide rate of oral cancer is lower than breast, prostate, and colon cancers. ${ }^{(1,4)}$ Fortunately, early diagnosis may increase the rate of survival by more than $80 \%$. ${ }^{(1,2)}$ Nevertheless, many patients are diagnosed at a late stage of the disease when the survival rate is poor (50-60\% 5 years post-treatment). Two important factors that cause late stage diagnosis are patients delay and professional delay. ${ }^{(5)}$ Patients delay comes from the low public awareness of oral cancer. ${ }^{(6)}$ Patients suffering from mouth ulcers often first request general advice from community pharmacies and their personnel (pharmacists and salespersons) ${ }^{(7)}$ as these are accessible places to visit and look for advice on a range of diseases, including mouth ulcers, ${ }^{(8)}$ friends or relatives can easily act as 'proxy consulters' on behalf of the patient ${ }^{\left({ }^{8,9)}\right.}$ and also advertisement in the press for proprietary products may encourage them to consult their pharmacist first. ${ }^{(7)}$ Previous investigations suggest that patients with symptoms of a probable oral cancer are not always advised by community pharmacies to seek professional medical care, especially when salespersons are involved. ${ }^{(7)}$ The other factor that plays a significant role in late stage diagnosis is the use of alternative remedies before seeking professional healthcare advice. ${ }^{(2)}$ Complementary and alternative medicine have attracted great attention during the last few decades. ${ }^{(10)}$ Despite the fact that in many countries educational training is not necessary in order to own an herbalist's shop, many people consider herbalists as expert health counselors. ${ }^{(2)}$ Relevant studies have defined that use of herbal medication has a significant correlation with patient delay for professional consultation; this is an independent predictor of prolonged patient delay. ${ }^{(11)}$ Traditional herbal medication use has been significantly associated with prolonged patient delay (hazard ratio [HR] 0.46, 95\% C.I. $0.28-0.76$ ) and also prolonged total delay (HR $0.45,95 \%$ C.I. $0.27-0.74) .{ }^{(12)}$ Since nearly $60 \%$ of oral cancers are diagnosed at stage III or IV in Iran, ${ }^{(11)}$ an urgent need is sensed for surveying the reasons of this delay. Therefore, the aim of this study was to investigate how community pharmacists, community pharmacy assistants and herbalists have been offering advice to patients seeking guidance on potentially malignant oral ulcers. The most relevant OTC (over-the-counter) preparations and herbal remedies which were prescribed to the patients were also assessed.

\section{Methods and Materials:}

A cross-sectional study by the standardized simulated patient approach was undertaken to investigate the recommendations given to a potential cancer patient at pharmacies and herbalists' shops in Rasht, capital city of Gilan province located in North of Iran, with 622, 209 populations unevenly distributed across $180 \mathrm{~km} 2$ area during March 2014. Annual percent change (APC) for oral and pharyngeal cancer was $1.36 \%$. Age standard rate (ASR) was 3.5 and 2.04 per 100 000 among males and females in the mentioned county. ${ }^{(13)}$ The ASR is a wighted mean of the agespecific rates; the weights are taken from population distribution of the standard population. The most frequently used standard population is the World Standard Population.

Annual Percent Change (APC) is one way to characterize trends in cancer rates over time. This means that cancer rates are assumed to change at a constant percentage of the rate of the previous year.

Chemists' addresses and phone numbers were obtained from Gilan pharmacists association, and herbalist shops' data were retrieved from web search. A total of 126 pharmacies and 14 herbalist's shops were identified and visited. Simulated patient/mystery shopper method was used where an individual interacts with the interviewee ac- 
cording to a previously prepared script: The introductory statement was "My father is 63 years old and he is a smoker who has a painful ulceration on his tongue for about 6 months which wasn't painful at first but is painful now. What would be your recommendation?" (2,5,6,7,8,9)

The responses from pharmacies and herbalist's shops staffs were noted and transferred to data sheets. The recommendations given by pharmacists, pharmacy assistants, and herbalists were reported separately and then grouped (respond rate). Recommended therapies and their administrations were also recorded. ${ }^{(2,7)}$ Response rate was estimated for each item in the checklist.

\section{Results:}

In this study, 126 community pharmacies and 14 herbalist's shops were visited. The results showed that pharmacies referred patients to a physician $(42 \%)$, a dentist $(28.6 \%)$ and one or the other $(2.4 \%)$ as the main recommendation. Also, $10 \%$ of pharmacies prescribed OTC drugs only and 11\% recommended medications in combination with referral to a medical or dental practitioner for guidance. In herbalist's shop, referring to a physician comprised $7.1 \%$ of cases and there were no referral to dentists. Recommendations of pharmacists, pharmacy assistants and herbalists on the management of an elderly person with a persistent oral ulcer are summarized in Table 1.

Table 1- Recommendations of pharmacists, pharmacy assistants and herbalists for the management of an elderly person with a persistent oral ulcer

\begin{tabular}{|c|c|c|c|}
\hline Answer & $\begin{array}{c}\text { Pharmacist } \\
\text { n }(\%)\end{array}$ & $\begin{array}{c}\text { Pharmacy } \\
\text { assistant } \\
\text { n }(\%)\end{array}$ & $\begin{array}{l}\text { Herbalist } \\
\mathrm{n}(\%)\end{array}$ \\
\hline $\begin{array}{l}\text { Referral to a } \\
\text { physician }\end{array}$ & $11(8.73 \%)$ & $42(33.3 \%)$ & $1(7.1 \%)$ \\
\hline $\begin{array}{l}\text { Referral to a } \\
\text { dentist }\end{array}$ & $14(11.1 \%)$ & $22(24.2 \%)$ & 0 \\
\hline $\begin{array}{l}\text { Referral to a } \\
\text { dentist or } \\
\text { physician }\end{array}$ & $1(0.8 \%)$ & $2(1.58 \%)$ & 0 \\
\hline $\begin{array}{l}\text { Prescribing an } \\
\text { OTC } \\
\text { medication }\end{array}$ & $4(3.17 \%)$ & $9(7.14 \%)$ & $11(78.6 \%)$ \\
\hline $\begin{array}{l}\text { Prescribing an } \\
\text { OTC medication } \\
\text { and referral to a } \\
\text { dentist/physician }\end{array}$ & $2(1.58 \%)$ & $12(9.52 \%)$ & 0 \\
\hline $\begin{array}{l}\text { Asking to see } \\
\text { the patient }\end{array}$ & $3(2.38 \%)$ & $4(3.17 \%)$ & $2(14.3 \%)$ \\
\hline
\end{tabular}

The most frequent OTC medications recommended at pharmacies were "Persica" mouthwash (38.4\%) and Triamcinolone paste $(15.4 \%)$ while in herbalist's shops there were Glycyrrhiza glabra (45.4\%) and Mentha piperita (18.2\%) (Table $2 \&$ $3)$.

Table 2- Most frequent recommendations of pharmacists and pharmacy assistants for treatment of a persistent oral ulcer

\begin{tabular}{lcc}
\hline Medication & Dosage form & $\mathrm{n}(\%)$ \\
\hline Persica & Mouthwash & $5(38.4 \%)$ \\
\hline Triamcinolone & Paste & $\begin{array}{c}2 \\
(15.4 \%)\end{array}$ \\
\hline Triamcinolone+Persica & Paste+ Mouthwash & $\begin{array}{c}2 \\
(15.4 \%)\end{array}$ \\
\hline Antihistamine & Tablet & $1(7.7 \%)$ \\
\hline $\begin{array}{l}\text { Triamcinolone+Persica+ } \\
\text { nystatin }\end{array}$ & Paste+ Mouthwash & $1(7.7 \%)$ \\
\hline Antibiotic & Tablet or Capsule & $\begin{array}{c}2 \\
(15.4 \%)\end{array}$ \\
\hline
\end{tabular}

Table 3- Herbalists' most frequent recommendations for treatment of a persistent oral ulcer.

\begin{tabular}{lc}
\hline Medicinal Plant & $\mathrm{n}(\%)$ \\
\hline Glycyrrhiza glabra & $5(45.4 \%)$ \\
\hline Mentha piperita & $2(18.2 \%)$ \\
\hline Matricaria chamomilla & $2(18.2 \%)$ \\
\hline Myrtus communis & $1(9.1 \%)$ \\
\hline Eugenia caryophyllata & $1(9.1 \%)$
\end{tabular}

As shown in Table 4, General Practitioner $(56.6 \%)$ received the highest level of referral among physicians while General dentist (66.7\%) and Oral and maxillofacial medicine specialist (19.4\%) received most of the referrals among dental specialists. 
Table 4- Most frequent patient referrals from community pharmacies in case of a persistent oral ulcer

\begin{tabular}{lccc}
\hline $\begin{array}{l}\text { Referral to a } \\
\text { physician }\end{array}$ & $\mathrm{n}(\%)$ & $\begin{array}{c}\text { Referral to a } \\
\text { dentist }\end{array}$ & $\mathrm{n}(\%)$ \\
\hline $\begin{array}{l}\text { General } \\
\text { Practitioner }\end{array}$ & $30(23.8)$ & $\begin{array}{c}\text { General } \\
\text { dentist }\end{array}$ & $\begin{array}{c}24 \\
(19.04)\end{array}$ \\
\hline internist & $16(12.7)$ & $\begin{array}{c}\text { Oral and } \\
\text { maxillofacial } \\
\text { Medicine } \\
\text { Specialist }\end{array}$ & $\begin{array}{c}7 \\
(5.55)\end{array}$ \\
\hline $\begin{array}{l}\text { Dermatologist } \\
\begin{array}{l}\text { Ear, nose and } \\
\text { throat } \\
\text { specialist }\end{array}\end{array}$ & $2(1.58)$ & Periodontist & 3 \\
\hline
\end{tabular}

\section{Discussion:}

Since early detection of oral cancer is important in increasing the rate of survival, the role of community pharmacies as the first place at which the patients with oral ulcer seek advice, is significant. In some African countries they provide services to over $80 \%$ of the population for achieving the goals of primary health care. The knowledge of the mentioned community is assumed to be eligible in the diagnosis, prevention or elimination of a physical, mental or social disease by World Health Organization (WHO, 1978a). ${ }^{(15)}$ Various studies have proposed that multiple factors have impact on diagnosis delay. The main factor is delay in seeking consultation or making an appointment. In societies with low socioeconomic status and impaired knowledge about delay in cancer diagnosis, herbalists may be predictors in delayed diagnosis. ${ }^{(12)}$ Pharmacy assistants with insufficient knowledge are always the first to face the patient's question. If patients had not received any prescription from their doctor, they would usually prescribe some OTC drugs.

In the present study, total referral rate by pharmacies equaled $73 \%$ comprising referrals to a primary medical care system such as a dentist, a physician and one or the other. Furthermore, Rogers et al have reported that $69 \%$ of pharmacies had the same advice for patients with an ulcer in his mouth for 4 weeks. ${ }^{(5)}$ In contrast, Scully et al, reported that less than $10 \%$ of community pharmacies referred patients to a doctor or a dentist and only $30 \%$ of the patients were referred in a similar study conducted in the USA. ${ }^{(8)}$ In pharmacies, $74.3 \%$ of patients were properly referred to a primary medical care system by pharmacists while this percentage was $72.5 \%$ for pharmacy assistants. These results indicate that pharmacy assistants are aware that an appointment with a doctor or dentist is imperative for patients with a persistent oral ulcer. Our results suggested that pharmacy assistants in this study had a higher level of knowledge on the necessity of referring the patients to a doctor or dentist compared with the results of a study by Evans and Gibbons ${ }^{(8)}$ who have reported that $82 \%$ of community pharmacists and $35 \%$ of pharmacy assistants had advised the patient to refer to a doctor or dentist.

According to our data, only $7.1 \%$ of herbalists' shops advised patients to visit a doctor and none of them recommended an appointment with a dentist. The results showed that herbalists regularly offer OTC medications to patients with oral ulcer (78.6\%) instead of referring them to primary care clinics. In a similar study by Varela-Centelles et al, only $2.6 \%$ of herbalists suggested the correct referral system and $86.4 \%$ recommended OTC remedies instead. ${ }^{(2)}$ Also the results of the study by Adebola et al showed that only $33.3 \%$ of herbalists were informed of oral cancer in $\mathrm{Ni}$ geria, ${ }^{(1)}$ while higher levels of awareness were reported in the United State (56\%). Nearly 10\% of the pharmacies surveyed in this study recommended OTC drugs only and $11 \%$ prescribed medications in combination with referral to a medical or dental practitioner for consultation. In another study by Evans and Gibbons, $17.7 \%$ of pharmacies prescribed OTC medications alone and $36.3 \%$ suggested medications in combination with referral to medical care professionals.

Unfortunately, this is a common concern in many countries where advice from the primary health care interface cause delay in diagnosis. The mentioned hindrance not only occurs in the case of oral cancer, but also may happen in other cancers with nonspecific initial signs. The most frequent OTC recommendation at pharmacies (38.4\%) was "Persica" mouthwash which is made of ethanol extracts from three medicinal plants including Salvadora persica $(30 \%)$, Achillea millefolium (25\%) and Mentha spicata (45\%) (Table 2)..$^{(16,17)}$ In herbalists' shops Glycyrrhiza glabra (45.4\%) was the most common remedy prescribed for oral ulcers (Table3). Though many indigenous plants have been used to cure bacterial or fungal diseases, ${ }^{(18,19)}$ these plants should be prescribed only 
by specialists or general practitioners in the treatment of oral ulcers.

Previous studies have shown that oral cancer is mainly a disease of the elderly. (2) For instance, $89 \%$ of all oral cancer cases diagnosed in Iran occur in people over 40 years of age with the average age of $61 .^{(14)}$ On the other hand, presenting to herbalists to receive herbal remedies is prevalent among elderly people. ${ }^{(2)}$ Studies have shown that in the USA, $12.9 \%$ of elderly patients use herbal medicines. ${ }^{(20)}$ This percentage was $19.1 \%$ to $41 \%$ in Sweden, $20 \%$ in the UK and $15.4 \%$ in Spain. ${ }^{(2)}$ Since herbalists generally recommended OTC medications to patients with potentially malignant oral ulcers instead of referring them to primary care clinics, it is apparent that they have potential role in patient diagnostic delay. Considering the fact that herbalists require no educational training in order to own a shop and visit patients in many countries including Iran, urgent need to increase their oral cancer awareness is obvious.

In conclusion, since community pharmacies are easily available to patients with oral ulcer to visit and look for advice, they have a good chance to identify potential oral cancer cases in early stage and refer them to primary care clinics for more thorough evaluations. In this study, the general awareness of pharmacists and their assistants was estimated to be equally high. Nevertheless more strict educational strategies are recommended for pharmacists and their assistants to improve consultation and referral policies.

\section{Conflicts of interest}

No conflict of interest has been declared.

\section{Acknowledgement}

We are thankful to those who helped us in this article including research center of Islamic Azad University, Dental Branch of Tehran.

\section{References:}

1.Adebola RA, Bamgbose BO, Adeoye JB, Amole TG. Awareness of Oral Cancer in a Northwestern Nigerian State: Assessing the Knowledge, Opinion, and Practice of Traditional Healers and Herbalists. J Oral Oncol 2013;1-7.

2.Varela-Centelles P, Pedrosa R, Lopez-Niño J, Sánchez M, Gonzalez-Mosquera A, Mendez A, et al. Oral cancer awareness at chemist's and herbalist's shops: New targets for educational interventions to prevent diagnostic delay. Oral Oncol 2012;48(12):1272-5.

3.Mehrotra R, Yadav S. Oral squamous cell carcinoma: etiology, pathogenesis and prognostic value of genomic alterations. Indian J Cancer 2006;43(2):60-6. 4.Greenlee RT, Hill-Harmon MB, Murray T, Thun M. Cancer statistics, 2001.CA Cancer J Clin 2006;11(6):15-36.

5.Rogers SN, Lowe D, Catleugh M, Edwards D. An oral cancer awareness intervention in community pharmacy. Br J Oral Maxillofac Surg 2010;48(7):498502.

6.Rogers SN, Pabla R, McSorley A, Lowe D, Brown JS, Vaughan ED. An assessment of deprivation as a factor in the delays in presentation, diagnosis and treatment in patients with oral and oropharyngeal squamous cell carcinoma. Oral Oncol 2007;43(7): 648-55.

7.Scully C, Gill Y, Gill Z. How community pharmacy staff manage a patient with possible oral cancer. Br J Oral Maxillofac Surg 1989;27(1):16-21.

8.Evans MJ, Gibbons AJ. Advice given in community pharmacies to patients with possible oral carcinoma. Br J Oral Maxillofac Surg 2005;43(3):253-5.

9.Hassell K, Noyce PR, Rogers A, Harris J, Wilkinson J. A pathway to the GP: the pharmaceutical'consultation'as a first port of call in primary health care. Fam Pract 1997;14(6):498-502.

10.Al-Windi A. Predictors of herbal medicine use in a Swedish health practice. Pharmacoepidemiol Drug Saf 2004;13(7):489-96.

11. Kerdpon, D, Sriplung H. "Factors related to delay in diagnosis of oral squamous cell carcinoma in southern Thailand." Oral Oncol 2001;37(2):127-31.

12. Scott SE, Grunfeld EA, McGurk M. "Patient's delay in oral cancer: a systematic review." Community Dent Oral Epidemiol 2006;34(5):337-43

13. Rabiei M, Basirat M, Rezvani SM. Trends in the incidence of Oral and Pharyngeal Cancer (ICD0014) in Guilan, North of Iran. J Oral Pathol Med 2016;45(4):275-80.

14. Sargeran K, Murtomaa H, Safavi SM, Vehkalahti $\mathrm{M}$, Teronen O. Malignant oral tumors in Iran: ten-year analysis on patient and tumor characteristics of 1042 patients in Tehran. J Craniofac Surg 2006;17(6): 1230-3

15. Elujoba A. A, Odeleye O. M, Ogunyemi C. M. Traditional medicine development for medical and dental primary health care delivery system in Africa. African Ethnomedicines Network 2005;2(1):46-61.

16.Rajabalian S, Mohammadi M, Mozaffari B. Cytotoxicity evaluation of Persica mouthwash on cultured human and mouse cell lines in the presence and 
absence of fetal calf serum. Indian J Dent Res 2009

;20(2):169-73.

17.Moeintaghavi A, Arab H, Khajekaramodini M, Hosseini R, Danesteh H, Niknami H. In vitro antimicrobial comparison of chlorhexidine, persica mouthwash and miswak extract . J Contemp Dent Pract 2012;13(2):147-52.

18.Shahidi Bonjar G.H, Aghighi S, Karimi Nik A. Antibacterial and antifungal survey in plants used in indigenous herbal-medicine of south east regions of Iran. J Biol Sc 2004;4(3) 405-412.

19. Kamal Rai A, Joshi R. Evaluation of antimicrobial properties of fruit extracts of Terminalia chebula against dental caries pathogens. Jundishapur Journal of Microbiology 2009; 2(3): 105-111.

20.Bruno JJ, Ellis JJ. Herbal use among US elderly: 2002 national health interview survey. Ann Pharmacother 2005;39(4):643-8. 